\title{
German agency to boost bioinformatics
}

[MUNICH] Only weeks after the publication of a paper pointing to major deficits in Germany's genome research effort, the Deutsche Forschungsgemeinschaft (DFG), Germany's main funding agency for university research, has launched its own programme in bioinformatics.

The DFG is keen to encourage German universities to shed rigid, discipline-orientated structures that have prevented them from embracing bioinformatics as an important new academic discipline, and done little to lessen the chronic shortage of German bioinformaticists.

The speed of the DFG's decision, and the flexible nature of the programme itself, have both surprised and pleased German scientists. But the initiative is also a deliberate test of the DFG's ability to practise what it preaches and display the flexibility required to run a loosely structured programme.

The programme will consider for funding any proposal that could help to increase German competitiveness in bioinformatics. Two or three of the best proposals will share DM50 million (US\$26 million) over five years; the money may be spent on either research infrastructure or salaries.

Universities are being called upon to link up with local non-university research institutes to create regional projects for either establishing or building up permanent research and training centres in bioinformatics. Such projects, says the DFG, may "even go as far as cooperation with industry".

Winning proposals will be those that can persuade the DFG that they will create internationally competitive bioinformatics centres which will ultimately survive on funds from other sources.

"Winners will have to demonstrate convincingly that their proposal will result in structural changes" within universities, says the DFG's Andreas Engelke. Their aim must be "to provide a complete environment for bioinformatics, from undergraduate and postgraduate teaching to research programmes".

The DFG is not used to handling such a loosely defined programme. But its launch is partly a response to criticism from an independent evaluation committee, which concluded that the DFG's rigidity was an obstacle to supporting new interdisciplinary subjects (see Nature 399, 395-396; 1999). "This bioinformatics initiative is a sort of test case for us, to see if we can be as flexible as we want the universities to be," says Engelke.

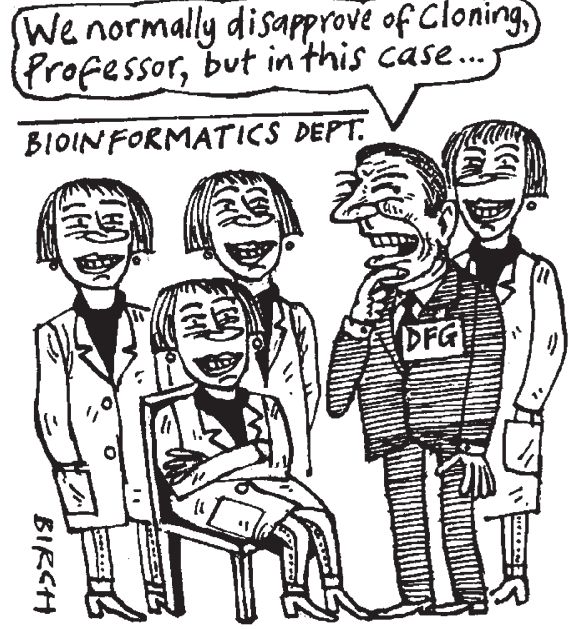

Peer Bork, head of bioinformatics at the European Molecular Biology Laboratory in Heidelberg and a group leader at the Max Delbrück Centre for Molecular Medicine in Berlin, says he is "very pleased" by the style of the programme. Bork was a member of the group of experts called together last December by DFG president Ernst-Ludwig Winnacker to discuss the future of genomics research in Germany.

The group's deliberations formed the 
basis of the DFG's position paper on genomics, which called on the government to provide an extra DM1 billion for genome research in the next five years (see Nature 399,622 ; 1999). The research ministry is now rethinking its genomics strategy and will publish a strategy paper in late summer. A major new programme in bioinformatics is expected to be announced.

But Bork warns that universities must take care when recruiting for any professorships created by the DFG programme. With few trained bioinformaticists available, and heavy competition from industry and other countries, "the new professorships could be filled with people with too little relevant experience: and this will be a problem for the training of the next generation".

These concerns are shared by Gerhardt Neuweiler, a former DFG president who is professor of zoology at the Ludwig Maximillian University in Munich, which is considering starting a course in bioinformatics. Neuweiler remembers when Germany "discovered ecology" 20 years ago. In the wave of the academic recruitment that followed, "many underqualified scientists were made professors, with the consequence that some areas of ecology are still very weak in Germany because of bad training".

There is general agreement that Germany, which has suffered a delayed start in all areas of genomic research, needs to generate armies of bioinformatics graduates as quickly as possible. Jens Reich, for example, one of Germany's few dedicated bioinformaticists and a professor at Berlin's Humboldt University, says the dearth of young bioinformaticists "is very apparent".

All academic establishments say recruitment has been extremely difficult. Bork, for example, still has seven unfilled positions in his bioinformatics group - now 15-strong - because he has been unable to find suitably qualified candidates.

A lack of qualified scientists has also delayed the start of the DFG's special Schwerpunkt programme in bioinformatics, the participants for which were selected at the end of last year. University researchers on the programme could not recruit postdocs to do the work, and a few weeks ago, in desperation, the DFG advertised the programme abroad, and is now starting to recruit.

In contrast, industry, which offers higher salaries, has escaped this problem. Reinhardt Schneider, a founder of Lion Biosciences, Germany's biggest bioinformatics company, says he has had no trouble recruiting scientists. But only a minority of his bioinformaticists are German. He therefore welcomes the DFG initiative, although he adds that "it would have been even nicer if it had happened a few years earlier".
Alison Abbott

\section{European embryology experts offer to advise on ethics of cloning}

[MUNICH] The European Society for Human Reproduction and Embryology (ESHRE) last week confirmed its view that human cloning should not be used at present for reproductive purposes, but that the development of cloning techniques for therapeutics should not be banned.

The society, meeting in Tours, France, offered to advise politicians on cloning. Its president, Lynn Fraser, professor of reproductive medicine at King's College London, says the membership is broad enough to be able to give independent expert advice.

In the immediate future, she says, the society could help the British parliament decide whether to allow cloning techniques for therapeutic purposes. Britain's Human Fertilization and Embryology Authority recommended to parliament in December that these techniques should be allowed.

Last month, however, a parliamentary committee said it needed more time to consider and would seek additional advice. After the birth in 1997 of Dolly the sheep, the ESHRE called for a five-year moratorium on the reproductive cloning of humans. 